\title{
Long-term follow up of varus osteotomy of the femur in patients with Perthes` disease in Erbil City
}

\begin{abstract}
Background and objective: Perthes disease is a condition in which a self-limiting
Background and objective: Perthes disease is a condition in which a self-limiting avascular problem affects the capital epiphysis of the femur with a variable course and outcomes. There are patients who definitely benefit from different treatment courses, either surgical or non-surgical, but better with surgical. This study aimed is to determine the outcome of varus derotational osteotomy procedure in the management of Perthes disease.
\end{abstract}

Methods: In this retrospective study, which was conducted in the orthopedic department of Erbil teaching hospital, 21 patients (22 hips) with Perthes` disease were enrolled over the period of 10- years, from 2008 to 2018. Varus derotational osteotomy to proximal femur was done for all 22 hips affected by Perthes disease in different radiological stages.

Results: Among the patients, $81.0 \%$ were males and right side of the hip was the most predominant $(52.4 \%)$ affected side. Partial limitation of hip movements with +ve Trendelenburg sign were the main clinical findings (52.4\%), especially among those aged $\leq 8$ years, males and left side affected patients (54.5\%, $72.7 \%$, and $63.6 \%$, respectively). Subluxation and metaphyseal resorption were the main radiological findings of the head of the femur (36.4\% and $31.8 \%$, respectively). Radiological stages of the patients mainly showed early fragmentation, late fragmentation, and early healing stages $(27.3 \%, 27.3 \%$, and $22.7 \%$, respectively). Postoperatively, $59.0 \%$ of the patients had a good prognosis (Stulberg grades 1 and 2), while $31.9 \%$ had a fair prognosis. Those aged $\leq 8$ years had a better prognosis with a significant statistical association between Stulberg classification and those with lateral pillar B \& B/C and early three radiological stages $(P=0.01$ and 0.005).

Conclusion: Open wedge varus femoral osteotomy is the treatment of choice and gives good results. The strongest predictor of outcomes is Stulberg classification in relation to age, lateral pillar classification, and preoperative radiological stages of the disease.

Keywords: Erbil; Perthes disease; Varus osteotomy; Lateral pillar classification; Stulberg classification.

\section{Introduction}

Legg-Calve-Perthes syndrome is a disorder of the hip in young children. It was described independently in 1910 by Legg, Calve, Perthes, and Waldenstrom. ${ }^{1}$ Over one hundred years have passed since the first three reports on Legg-Calvé-Perthes disease (LCPD) were published. It is a disease mostly affecting children between 4 to 12 years old, but the disease's etiology has not been established, and there is no consensus on the optimal treatment. ${ }^{2,3}$ Males are affected 4-5 times more often than females, and about $5 \%$ of all the diagnosed cases develop the disease bilaterally. ${ }^{4}$ LCPD is idiopathic osteonecrosis of the femoral head that may lead to femoral head deformity and osteoarthritis. There is no reliable way to predict the prognosis due to the great variation in the disease behavior in different hips. ${ }^{2,5}$ Perthes' disease is

${ }^{1}$ Department of Surgery, College of Medicine, Hawler Medical University, Erbil, Iraq.

* Correspondence: Zainababdulwahab@yahoo.com 
a self-limiting disease of children characterized by interruption of the blood supply to the capital femoral epiphysis resulting in necrosis of the epiphysis. ${ }^{3,6}$ The vascular occlusion is temporary; complete re-vascularization of the epiphysis occurs over 2-4 years if the child is under 12 years of age at onset of the disease. ${ }^{3}$ The course and prognosis of Perthes' disease are difficult to predict. The prognosis of the disease depends on the age of the patient at the time of the presentation, the height of the lateral pillar of the capital epiphysis, range of motion of the hip joint, the sphericity of femoral head, and congruency at skeletal maturity. ${ }^{7}$ Surgical containment has become widely accepted as the best method for treating Legg- Calve-Perthes disease (LCPD). Containment treatment is designed to center the femoral head within the acetabulum during the period of biologic plasticity. ${ }^{8}$ This allows the acetabulum to serve as a mold during the healing process. The most common methods for surgical containment have been either proximal femoral varus osteotomy or Salter innominate osteotomy. Either of these methods may provide adequate containment in mild to moderate LCPD, but they can be problematic in more severe cases. ${ }^{8-10}$. Studies comparing different treatment methods are reliable only in groups with similar prognostic factors. Two prospective multicenter studies have been published, one from the United States in 2004 and from Norway in 2008. ${ }^{9,11}$ In the Norwegian study, results of the 5-years follow up of patients older than 6 years, the degree of sphericity of the femoral head was better in children treated with femoral varus osteotomy than in those treated with physiotherapy or abduction orthosis. ${ }^{12}$ There is scarce data on the postoperative follow-up of Perthes disease in Iraq and Kurdistan region up to the researcher's knowledge. Accordingly, the researcher sought to conduct such research to determine the outcome of varus derotational osteotomy procedure in the management of Perthes disease, considering the sphericity of the head of the femur and its subluxation as a main prognostic factor according to Stulberg's classification.

\section{Methods}

This retrospective study was conducted in the orthopedic department of Erbil teaching hospital, which is the second main teaching hospital in Erbil governorate. In this study, 21 patients with Perthes' disease were enrolled, over the period of 10- years, from 2008 to 2018. Patients aged 6-12 years, including 17 males and 4 females, involving ten hips on the left side and 12 hips on the right side (one patient had bilateral Perthes disease). Those aged below 6 years and above 12 years, patients with severe stiffness of all hip movement, and active infection of the hip and the femur were excluded from the study. All the patients presented primarily with antalgic gait, and their Tendelenburg test was positive, except three of them. In this study, we depend on the lateral pillar classification system, which is based on radiographical changes in the lateral portion of the femoral head when it enters the fragmentation stage, as seen in antero-posterior view. ${ }^{13}$ Radiological signs act as an indicator, which affects the treatment and prognosis of all the involved patients in the study. Theses signs include metaphysical resorption and subluxation of the femoral head. Gage sign is a V-shaped lucent defect at the lateral portion of the epiphysis and/or adjacent metaphysis. It is pathognomonic for Legg-CalvePerthes disease. ${ }^{14}$ Varus derotational osteotomy to proximal femur was done for all 22 hips affected by Perthes disease in different radiological stages according to Waldenstrom classification ${ }^{15}$ and as follows:

Stage i: Sclerotic, (including $A$ as early and $B$ as late sclerotic stages), with good prognosis

Stage ii: Fragmentation, (including Aas 
early and $B$ as late fragmentation stages), with good prognosis

Stage iii: Healing, (including $A$ as early and $B$ as late healing stages), with bad prognosis.

Stage iv: Remodeling, with bad prognosis.

All the involved 22 hips were $x$-rayed pre operatively, with lower extremities in internal rotation and parallel to each other, in addition to the abduction of the extremities, which brings about the desired containment of the femoral head. The degree of abduction was expressed by the angle formed by the shaft of femur and the vertical line parallel to the midline of the pelvis. This angle represents the desired angle of the osteotomy. ${ }^{16}$ All the patients underwent open wedge varus derotational osteotomy of the proximal femur, with or without soft tissue release (Adductor tenotomy). ${ }^{17}$ Postoperatively, the children were kept in bed for at least 6 weeks, without using Plaster of Paris (PoP) spica and without weight bearing, followed by encouraging them to walk with two crutches supported by graduate exercise. Later on, they were followed up every two months in the first year and finally once every year. For long term follow up, 0000orthopedicians depend on Stulberg radiological grading of the patients. Stulberg radiological grading has five grades starting from grade 1, which indicates good prognosis ending by grade $\mathrm{V}$ that indicates very bad prognosis. ${ }^{18}$ Verbal approval was obtained from the parents of all the patients enrolled in this study; in addition, the study was approved by the research ethics committee of the College of Medicine- Hawler Medical University. The collected data was entered into excel sheet, filtered and cleaned, transferred into the statistical package for the social sciences (version 19) for statistical analysis using frequencies, percentages, and Chi square test to find the association between different variables considering $P$ value $\leq 0.05$ as statistically significant.

\section{Results}

Clinical preoperative profile of the patients:

A total of 21 patients with Perthes disease were enrolled in the current study; their age ranged from 6 to 12 years, with a mean age \pm SD of $8.57 \pm 1.86$ years. The clinical profile of the patients showed that more than half $(52.4 \%)$ of the patients aged less than 8 years. Among the patients, $81.0 \%$ were males with a male to female ratio of $4.25: 1$. The right side of the hip was the most predominant affected side, followed by the left and bilateral sides $(52.4 \%$, $42.9 \%$, and $4.7 \%$, respectively). Partial limitation of hip movements with +ve Trendelenburg sign was the main clinical findings $(52.4 \%)$ of the patients, especially among those ages less than 8 years, females and left side affected patients $(54.5 \%, 75.0 \%$, and $77.8 \%$, respectively). Limitation of all hip movements with +ve Trendelenburg sign was the second main clinical findings among $33.3 \%$ of the patients with more prevalence among those aged 8-12 years, males and those who had right sided affected hip (57.1\%, $35.3 \%$, and $36.4 \%$, respectively), Table 1 .

\section{Preoperative radiological profile of the hips:}

Lateral pillar classification of the patients revealed that half $(50.0 \%)$ of the patients had $\mathrm{C}$, and $36.4 \%$ of them were classified having $B / C$. In comparison, only $13.6 \%$ had B. Subluxation and metaphyseal resorption were the main radiological findings of the head of the femur $(36.4 \%$ and $31.8 \%$, respectively), with only two cases $(9.1 \%)$ showed Gages sing only. The radiological stages of the patients mainly showed early fragmentation, late fragmentation, and early healing stages $(27.3 \%, 27.3 \%$, and $22.7 \%$, respectively) (Table 2 and Figure 1). 
Table 1: Clinical preoperative profile of the patients $(n=21)$.

\begin{tabular}{lcccc}
\hline Variables & $\begin{array}{c}\text { Clinical profile } \\
\text { No. \& (\%) } \\
\text { movements with } \\
\text { TDB +ve * }\end{array}$ & $\begin{array}{c}\text { Partial limitation of } \\
\text { hip movements } \\
\text { with TDB +ve }\end{array}$ & $\begin{array}{c}\text { Partial limitation of } \\
\text { hip movements } \\
\text { with TDB -ve }\end{array}$ & \\
\hline $\begin{array}{l}\text { Age groups } \\
<8 \text { years }\end{array}$ & $3(27.3)$ & $6(54.5)$ & $2(18.2)$ & $11(52.4)$ \\
$\begin{array}{l}\text { 8-12 years } \\
\text { Gender }\end{array}$ & $4(57.1)$ & $5(45.5)$ & $1(33.3)$ & $10(47.6)$ \\
Males & $6(35.3)$ & $8(47.1)$ & $3(17.6)$ & $17(81.0)$ \\
$\begin{array}{l}\text { Females } \\
\text { Side of the affected limb } \\
\text { Right }\end{array}$ & $1(25.0)$ & $3(75.0)$ & $0(0.0)$ & $4(19.0)$ \\
Left & $4(36.4)$ & $4(36.4)$ & $3(27.2)$ & $11(52.4)$ \\
Both & $2(22.2)$ & $7(77.8)$ & $0(0.0)$ & $9(42.9)$ \\
Total & $1(100.0)$ & $0(0.0)$ & $0(0.0)$ & $1(4.7)$ \\
\hline
\end{tabular}

* TDG: Trendelenburg sign

**: Column percentage

Table 2: Preoperative radiological profile of the hips.

\begin{tabular}{lc}
\hline Radiological findings & No. (\%) \\
\hline Lateral pillar & $3(13.6)$ \\
B & $11(50.0)$ \\
C & $8(36.4)$ \\
B/C & \\
Head at risk & $8(36.4)$ \\
Subluxation & $7(31.8)$ \\
Metaphyseal resorption & $4(18.2)$ \\
Subluxation and metaphyseal resorption & $2(9.1)$ \\
Gages sign & $1(4.5)$ \\
Subluxation, metaphyseal resorption\& & \\
Gages sign & \\
Stages & $3(13.6)$ \\
Sclerotic stage & $6(27.3)$ \\
Early fragmentation & $6(27.3)$ \\
Late fragmentation & $5(22.7)$ \\
Early healing stage & $2(9.1)$ \\
Late healing stage & $\mathbf{2 2 ( 1 0 0 . 0 )}$ \\
Total & \\
\hline
\end{tabular}


Postoperative radiological findings:

Following the patients in the postoperative period revealed that $59.0 \%$ of the patients had good prognosis (Stulberg grades 1 \& 2 ), while $31.9 \%$ of them had fair prognosis (Stulberg grade 3), and only two cases had bad prognosis (Stulberg grades 4 \& 5). About $59.0 \%$ of the cases had a central edge angle of $26^{\circ}-40^{\circ}$ followed by those having $\leq 25^{\circ}$ and those with $>40^{\circ}(31.8 \%$ \& $9.1 \%$, respectively). More than half $(54.6 \%)$ of the patients showed no any postoperative abnormalities, $31.8 \%$ had overriding of the great trochanter, and short neck and $9.1 \%$ of them had short neck only (Figures 2, 3 and Table 3).

Table 3: Postoperative radiological findings of the patients.

\begin{tabular}{lc}
\hline Radiological findings & $\begin{array}{c}\text { No. of the hips } \\
\text { No. \& (\%) }\end{array}$ \\
\hline Stulberg grades & $13(59.0)$ \\
Good prognosis & $7(31.9)$ \\
Fair prognosis & $2(9.1)$ \\
Bad prognosis & \\
Central edge & $7(31.8)$ \\
$\leq 25^{\circ}$ & $13(59.0)$ \\
$26-40^{\circ}$ & $2(9.1)$ \\
$>40^{\circ}$ & \\
Others abnormalities & $12(54.6)$ \\
No abnormalities & $2(9.1)$ \\
Short neck & $7(31.8)$ \\
Overriding of great trochanter and short neck & $1(4.5)$ \\
Abduction hinge & $\mathbf{2 2 ( 1 0 0 . 0 )}$ \\
Total & \\
\hline
\end{tabular}
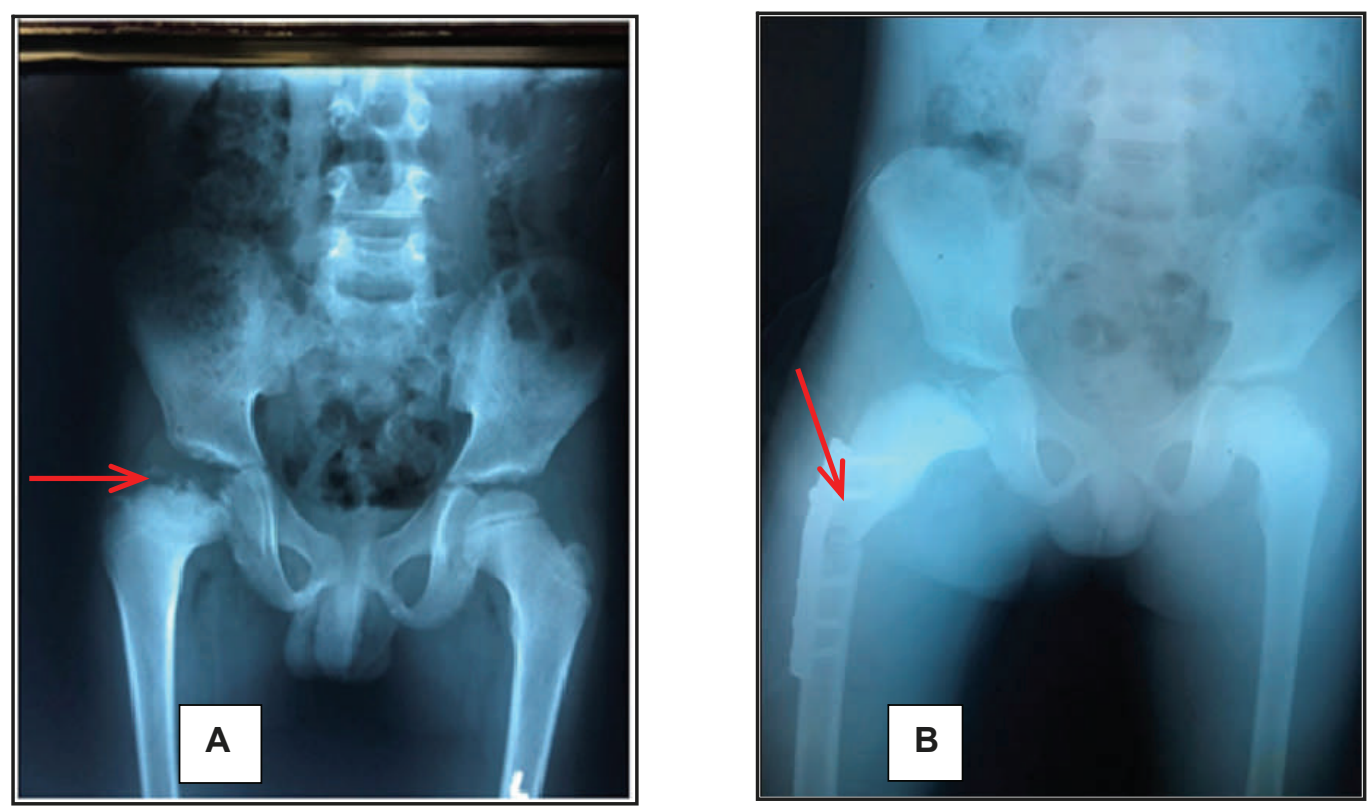

Figure 1: 8 years Perthes patient, A: Sings of late fragmentation \& lateral pillar $C$ with evidence of subluxation, B: Open wedge varus osteotomy. 

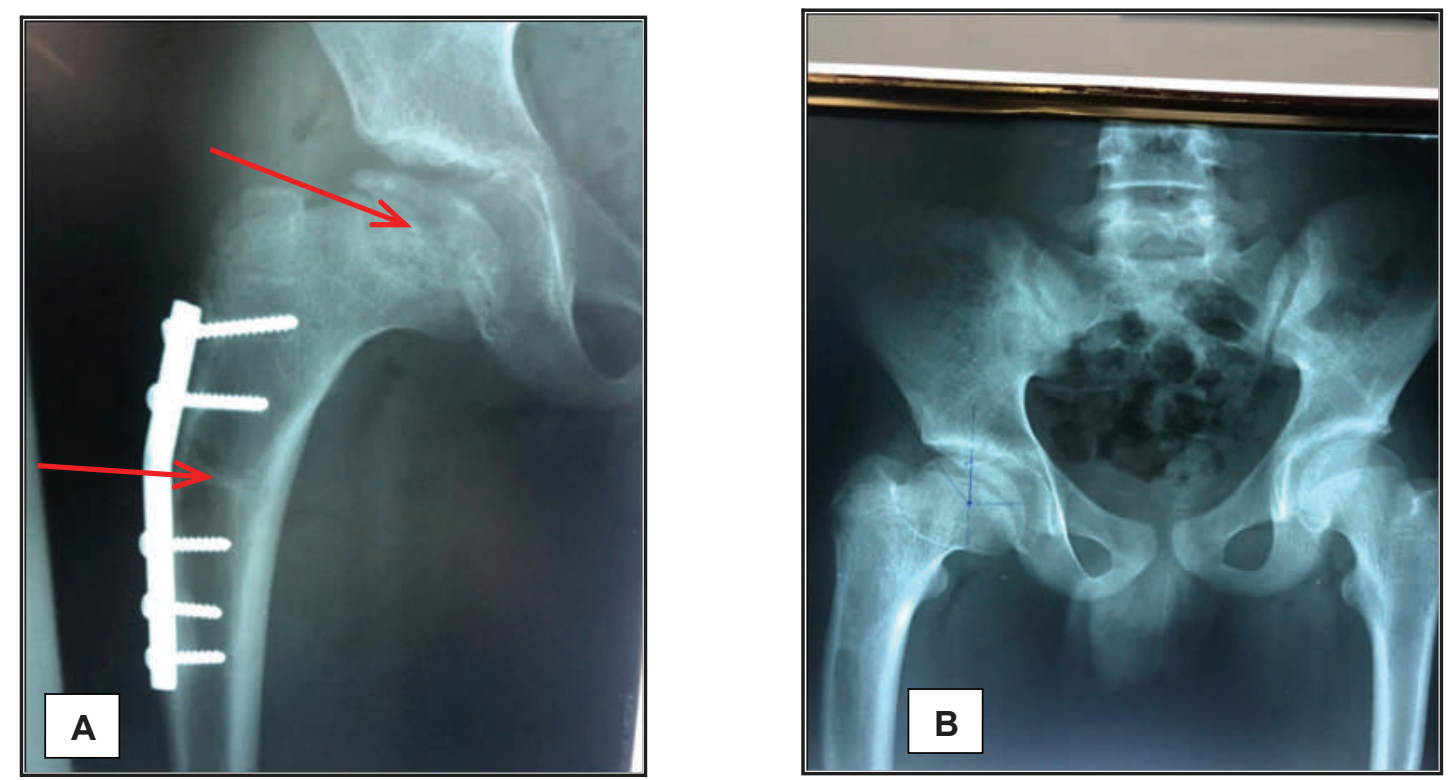

Figure 2: 8 years Perthes patient, A: Sings of good healing postoperatively, B: After removal of the plate.
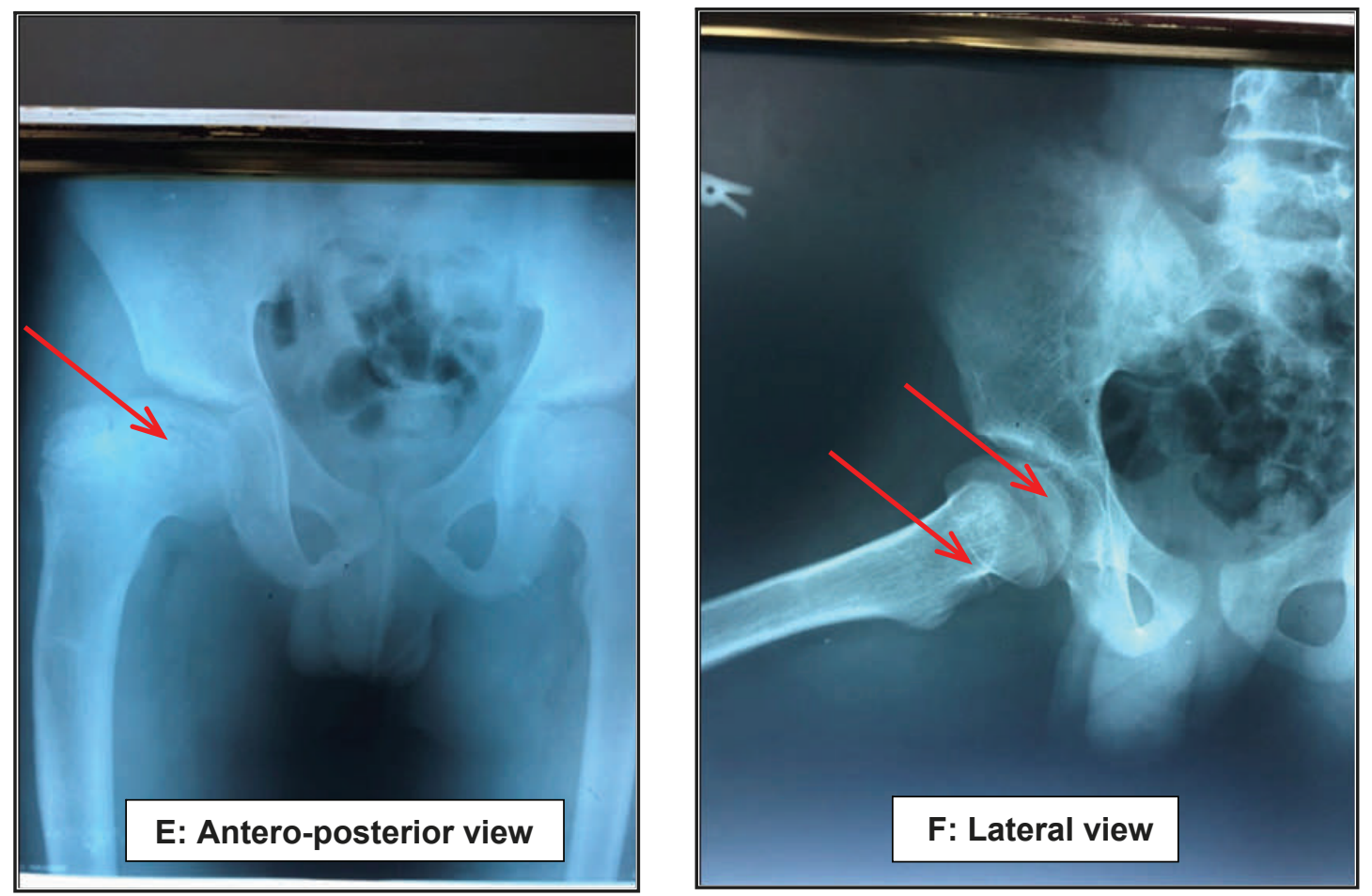

Figure 3: Shortening of the neck with spherical congruent head. 
Association of Stulberg classification to the lateral pillar and radiological stages of the patients

Those aged $<8$ years had achieved better prognosis compared to those 8-12 years old $(63.6 \% \quad \& 50.0 \%$, respectively), while those aged more than 8 years had higher fair prognostic results compared to those under 8 years $(40.0 \% \& 27.3 \%$, respectively) with no significant statistical association $(P=0.817)$, Figure 4 . Those with lateral pillar $B \& B / C$ had significantly better prognosis compared to those with lateral pillar $\mathrm{C}(P=0.01)$. Also, those with the first three radiological stages (including sclerosis, early and late fragmentation) had significantly $(P=0.005)$ a better prognosis compared to those having early or late healing stages (Table 4).

Table 4: Stulberg classification according to the lateral pillar and radiological stages of the hips.

\begin{tabular}{|c|c|c|c|c|}
\hline \multirow{2}{*}{$\begin{array}{l}\text { Variables } \\
\text { Lateral pillar }\end{array}$} & \multicolumn{3}{|c|}{$\begin{array}{c}\text { Stulberg classification } \\
\text { No. \& (\%) }\end{array}$} & \multirow{2}{*}{$\begin{array}{c}P \text { value * } \\
0.01\end{array}$} \\
\hline & Good & Fair & Bad & \\
\hline$B \& B / C$ & $10(90.9)$ & $1(9.1)$ & $0(0.0)$ & \\
\hline $\mathrm{C}$ & $3(27.3)$ & $6(54.5)$ & $2(18.2)$ & \\
\hline Radiological stages & & & & 0.005 \\
\hline Sclerotic \& Fragmentation stages & $12(80.0)$ & $3(20.0)$ & $0(0.0)$ & \\
\hline Healing stage & $1(14.3)$ & $4(57.1)$ & $2(28.6)$ & \\
\hline Total & $13(59.1)$ & $7(31.8)$ & $2(9.1)$ & $22(100.0)$ \\
\hline
\end{tabular}

*: Fisher's exact test

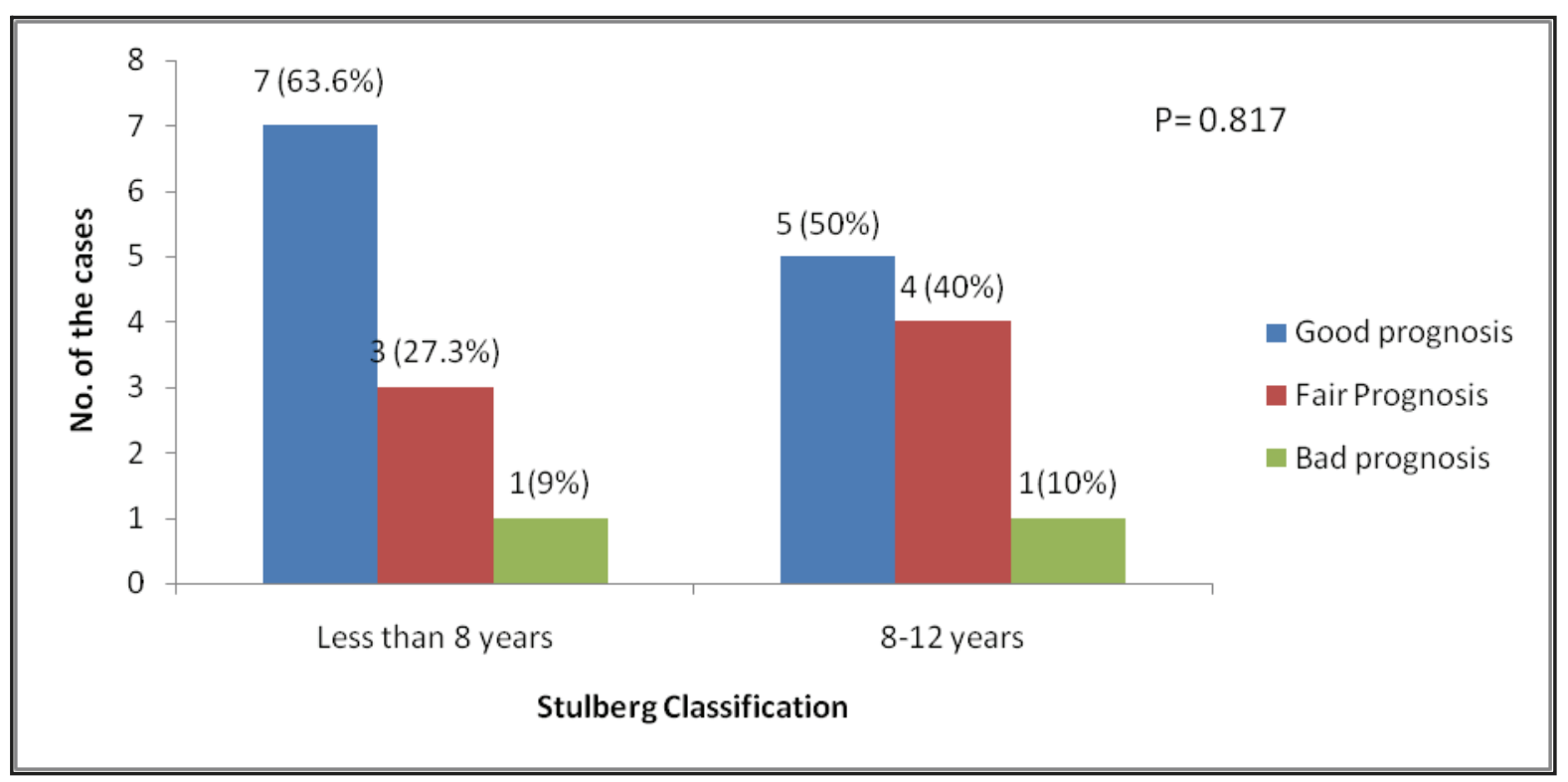

Figure 4: Association of Stulberg classification to age groups of the patients. 


\section{Discussion}

Perthes disease is a condition in which a self-limiting avascular problem affects the capital epiphysis of the femur with a variable course and outcomes. It has been shown commonly, however, that there are patients who definitely benefit from different treatment courses, either surgical or non-surgical, but better with surgical. ${ }^{19}$ In this study majority of the patients were males, and the right side of the hip was the most predominant affected side. Studies in Iraq (Dohuk and Basrah) revealed that males suffered more, but the left side of the hip was the most affected one. ${ }^{4,6}$ Another study in the USA showed that the disease is mostly unilateral $(89.2 \%)$, more common in boys $(81.4 \%)$ than girls $(18.6 \%)$, and right and left hip involvement is similar. ${ }^{20}$ These differences and similarities could be due to the significant variability within countries, cities, and males who are more involved in hyperactive activities than females. Our study had shown that more than half of the patients had partial limitation of hip movements with +ve Tendelenburg sign, especially among those ages less than 8 year, males and left side affected patients. Limitation of all hip movements with +ve Tendelenburg sign was the second main clinical findings among one-third of the patients with more prevalence among those aged 8-12 years, males and those who had right sided affected hip. A study in Sudan revealed that $39.5 \%$ of the patients had no limitation of the movement, and limitation of internal rotation and abduction was the main finding (48. 84\%) among patients with limitation of hip movement. ${ }^{21}$ These variations could be due to the different sample size, age variations, and other social and cultural factors in addition to access to health care facilities. Our study showed that the lateral pillar classification of the patients revealed that half of the patients had $\mathrm{C}$, and more than one-third of them were classified having $B / C$. A study in China revealed that there were $12(23.5 \%)$ patients in grade B, $24(47.1 \%)$ in grade $B / C$, and $15(29.4 \%)$ in grade C. ${ }^{22}$ Another study in France showed that $61.9 \%$ of the patients were grade B, $19.0 \%$ were grade $\mathrm{B} / \mathrm{C}$, and other $19.0 \%$ were grade $\mathrm{C}^{23}$ Also, the study revealed that subluxation and metaphyseal resorption were main radiological findings of the head of the femur. Radiological stages of the patients mainly showed early fragmentation, late fragmentation, and early healing stages, while a study in France revealed almost similar results, where $90.5 \%$ of the patients were at early fragmentation stage, and only $9.5 \%$ were at the end of the fragmentation/ beginning of reconstruction stage. ${ }^{22}$ Following the patients in the postoperative period revealed that more than half of the patients had good prognosis (Stulberg grades $1 \& 11)$. In contrast, nearly one-third of them had fair prognosis (Stulberg grade 111), and only two cases (less than 10\%) had bad prognosis (Stulberg grades $1 \mathrm{~V} \& \mathrm{~V}$ ). Almost similar results were reported in a Japanese study, where radiographic outcome at final follow-up of 130 patients was good in 82 hips (63\%), fair in 40 hips $(31 \%)$, and poor in 8 hips $(6 \%) .{ }^{24}$ another study in Korea showed different results, out of 12 patients revealed Stulberg gradel, 0 cases; Stulberg grade II, 4 cases (34\%); Stulberg III, 7cases (58\%); Stulberg IV, 1 case $(8 \%)$; and Stulberg $\vee, 0$ cases. ${ }^{10}$ Our study showed that more than half of the cases had a central edge angle of $26^{\circ}-40^{\circ}$ followed by those having $\leq 25^{\circ}$ and those with $>40^{\circ}(31.8 \% \& 9.1 \%$, respectively). This is inconsistent with results of a study in Korea, where the mean angular correction of the varus osteotomy in group A was $20^{\circ}$ and the mean medial displacement was $21 \%$, the angular correction of valgus osteotomy in group B was $28^{\circ}$, and lateral displacement was $41 \% .{ }^{25}$ Also, the study showed that more than half of the patients had no any postoperative abnormalities, $31.8 \%$ had overriding of the great trochanter, and short neck and $9.1 \%$ of them had short neck only. A study in Iran showed various 
radiological signs in patients such as flattening of the femoral head in $6(20.7 \%)$ patients, ace-tabular changes in $4(13.8 \%)$ patients, femoral neck short-ening in 10 $(34.5 \%)$ patients, trochanter enlargement in $6(20.7 \%)$ patients, abnormality in femoral neck angel in 22(75.9\%) patients, and femoral head enlargement in $8(27.6 \%)$ patients. ${ }^{26}$ Also, a study in Basrah, Iraq, that involved 12 patients with 14 hips treated by femoral varus derotation osteotomy showed that $42.1 \%$ had no shortening, another $42.1 \%$ had shortening up to $1 \mathrm{~cm}$, and $14.4 \%$ had shortening between $1-2 \mathrm{~cm} .{ }^{6}$ Another study in China, clinical evaluation at final follow-up of 51 patients showed that $76.5 \%$ of the patients had a normal passive range of hip movement without pain and $33.3 \%$ had leg length discrepancy, ranging from 0.5 to $2.0 \mathrm{~cm} .^{22}$ Varus osteotomy is criticized because it might cause some undesired shortening, but this may be reduced by lateral opening wedge osteotomy. Femoral varus osteotomy is a simple procedure that allows femoral head centering deep within the acetabulum avoiding impingement against the acetabular edges, but it adds to the shortening already present by femoral head fragmentation and collapse. ${ }^{5}$ The study showed that those aged $<8$ years had achieved better prognosis (Stulberg stages 1 \& 11) compared to those 8-12 years old. However, those aged more than 8 years had higher fair prognosis (Stulberg stage 111) results than those under 8 years with no significant statistical association $(P=0.817)$. Almost similar results were reported in a study in Norway, where age at diagnosis was strongly associated with the radiological outcome; the younger the patient at the onset of diagnosis, the better the outcome, since the outcome in children below six years of age was significantly better than in those aged six and more $(P<0.001){ }^{9}$ Those with lateral pillar B\& $\mathrm{B} /$ $C$ had a significantly better prognosis compared to those with lateral pillar $C$ $(P=0.01)$. Similar results were reported in a study in England that showed hips with
Catterall group I and II and lateral pillar group $A$ and $B$ had significantly better results. ${ }^{27}$ Also, those with the first three radiological stages (including sclerosis, early and late fragmentation) had significantly $(P=0.005)$ better good prognosis, compared to those having early or late healing stages. Almost similar results were reported in a study in the USA, where the modified Waldenström classification system for staging of Legg-Calvé-Perthes disease proved to have an important to an almost perfect agreement amongst and within observers through multiple rounds of study. ${ }^{28}$ It has been shown that the duration of the disease is significantly shortened through by-passing the stage of fragmentation when a varus osteotomy is performed in the stage of avascular necrosis. ${ }^{3}$ An important conclusion is that for every influential factor, there are exceptional cases with bad consequences in spite that the determining factor favors good prognosis; that is to say, the surgeon cannot secure good prognosis in every case. The strength points of this study are that it is the first study done in Kurdistan region of Iraq addressing this important problem in the community. Furthermore, in this study, the author evaluated the relation between various prognostic factors and the final outcome to provide a base that could allow better prediction of the outcome of Perthes disease in the region. There were some limitations in our study. The sample size was small in this study. Therefore, the surgical outcomes might not be the reflex of surgery outcome in all patients with Legg-Calve'-Perthes disease in our community. In addition, patients' age at surgical intervention varied, which might had a dramatic impact on disease presentation and the outcome. Also, the non-compliance of patients' parents was another problem that made the process of postoperative follow up very difficult. So many patients were lost for follow up and consequently affected the study sample. The follow-up period had not been 
sufficient and rather difficult to assess the results fully. Finally, too many disparities between different studies made statistical comparison difficult.

\section{Conclusion}

According to the results of this study, open wedge proximal femoral varus osteotomy gives good results in children $\leq$ 8years, fair results among those aged $\geq 8$ years old, those with lateral pillar B \& B/C and those with the first three radiological stages (including sclerosis, early and late fragmentation). However, the study concluded that the strongest predictor of outcomes is Stulberg classification in relation to age, lateral pillar classification, and pre-operative radiological stages of the disease.

\section{Competing interests}

The author declares no competing interests.

\section{References}

1. Weinstein SL, Flyn JM. Pediatric orthopedics. $7^{\text {th }}$ ed. Philadelphia: Wolters Kluwer; 2014. P.1112-64.

2. Mazloumi SM, Ebrahimzadeh MH, Kachooei AR. Evolution in diagnosis and treatment of Legg-Calve-Perthes disease. Arch Bone Joint Surg 2014; 2(2):86-92.

3. Joseph B. Management of Perthes' disease. Indian J Orthop 2015; 49(1):10-6.

4. Alsufi SM. A comprehensive epidemiological study of Perthes disease in Duhok Governorate. Dyala J Med 2013; 5(2):96-106.

5. Elgohary HE, Abouelnas BA. Perthes' disease: prediction of the outcome. (Accessed October 1, 2018, at https://www.researchgate.net/publication/ 327013654_Perthes'_disease_prediction_of_the outcome).

6. Al-Mukhtar AW, Kareem MJ. Femoral versus derotation osteotomy in management of Perthes disease. Bas J Surg 2003; 9(1):60-70.

7. Singh A, Srivastava RN, Shukla P, Pushkar A, Ali S. Management of late onset Perthes: Evaluation of distraction by external fixator: 5-Year follow up. Adv Orthop 2014; 2014: 135236.

8. Nguyen NA, Klein G, Dogbey G, McCourt JB, Mehlman CT. Operative versus nonoperative treatments for Legg- Calve-Perthes disease: a meta-analysis. J Pediatr Orthop 2012; 32(7):697-705.
9. Wiig O, Terjesen T, Svenningsen S. Prognostic factors and outcome of treatment in Perthes' disease: a prospective study of 368 patients with five five-year follow-up. J Bone Joint Surg $\mathrm{Br}$ 2008; 90(10):1364-71.

10. Lim KS, MD, Shim JS. Outcomes of combined shelf acetabuloplasty with femoral varus osteotomy in severe Legg-Calve-Perthes (LCP) disease: Advanced containment method for severe LCP disease. Clin Orthop Surg 2015; 7(4):497-504.

11. Herring JA, Kim HT, Browne R. Legg-Calve'-Perthes disease. Part II. Prospective multicenter study of the effect of treatment on outcome. J Bone Joint Surg Am 2004; $86: 2121-34$.

12. Terjesen $T$, Wiig $O$, Svenningsen $S$. Varus femoral osteotomy improves sphericity of the femoral head in older children with severe form of Legg-Calve'-Perthes disease. Clin Orthop Relat Res 2012; 470:2394-401.

13. Herring JA, Neustadt JB, Williams JJ, Early JS, Browne $\mathrm{RH}$. The lateral pillar classification of Legg-Calve-Perthes disease. J PediatrOrthop 1992; 12(2):143-50.

14. St- AmantM, Samir B. Gages sign. (Accessed November 8, 2018, at https://radiopaedia.org/ articles/gage-sign).

15. Alshryda S, Banaszkiewicz PA, Jones S. Postgraduate PaediatricOrthopaedics: The candidate's guide to the FRCS ( $\mathrm{Tr}$ and Orth) examination. $5^{\text {th }}$ ed. Cambridge, United Kingdom: Cambridge University Press; 2014.

16. Canale ST, Beaty JH. Campbell's operative orthopedics. $12^{\text {th }}$ ed. Philadelphia: Elsevier; 2013.

17. Joseph B, Nayagam S, Loder R, Torode I. Pediatric orthopedics. A system of decision- making. London: Hoderarnold; 2009. P.463-72.

18. Stulberg SD. Cooperman DR. Wallensten R. The natural history of Legg- Calve-Perthes disease. J Bone Joint Surg AM 1981; 63:1095.

19. Mohan-Kumar EG, Yathisha-Kumar GM, Rasheed M A. Outcome of closed wedge varus derotation osteotomy with trochanteric apophysiodesis in Perthes disease. Indian J Orthop 2018; 52:616-24.

20. Loder RT, Skopelja EN.The Epidemiology and demographics of Legg-Calves-Perthes' disease. ISRN Orthop 2011; 2011:04393.

21. Shaheen S, Awed A. Perthes Disease, results of conservative at Soba University Hospital. Sudan JMed Sci 2015: 10(3):85-91.

22. Li WC, Xu RJ. Lateral shelf acetabuloplasty for severe Legg-Calvé-Perthes disease in patients older than 8 years: A mean eleven-year follow-up.Medicine 2016; 95(45):e5272.

23. Pecquery R, Laville JM, Salmeron F. Legg-Calvé-Perthes disease treatment by augmentationacetabuloplasty. Orthop Traumatol Surg Res 2010; 96(2):166-74. 
24. Iwamoto M, Nakashima $Y$, Nakamura T, Kohno Y, Yamaguchi R, Takamura K. Clinical outcomes of conservative treatment with a non-weightbearing abduction brace for Legg-Calvé-Perthes disease. J Orthop Sci 2018;23(1):156-60.

25. Kwang-Won P, Ishani PS, Ashok KR,Tae-Jin L, Hae-Ryong S.Proximal femoral osteotomy in Legg-Calvé-Perthes disease using a monolateral external fixator: surgical technique, outcome, and complications. J Pediatr Orthop B 2017; 26(4):329-35.

26. Moghadam MH, Moradi A, Omidi-Kashani F. Clinical outcome of femoral osteotomy in patients with Legg-Calve'-Perthes disease. Arch Bone Joint Surg 2013; 1(2):90-3.

27. Perry DC, Skellorn PJ, Bruce CE. The lognormal age of onset distribution in Perthes' disease: an analysis from a large well-defined cohort. Bone Joint J 2016; 98-B(5):710-4.

28. Hyman JE, Trupia EP, Wright ML, Matsumoto $\mathrm{H}$, Jo $\mathrm{CH}$, Mulpuri $\mathrm{K}$. Inter observer and intra observer reliability of the modified Waldenström classification system for staging of Legg-CalvéPerthes disease. J Bone Joint Surg Am 2015; 97(8):643-50. 